\title{
The Impact of Knowledge Behavioural Factors on Tacit Knowledge Retention: Empirical Study in Oil and Gas Industry
}

\section{AbdulGhani Abdullah Gaghman}

The Bucharest University for Economic Studies, Bucharest, Romania

\section{Abstract}

Organisation need be more effective in retaining the tacit knowledge (know-how and know-what) and made it accessible for another staff to be more productive and enable management to make better decisions. Relying on explicit knowledge and old-style training courses is simply no longer effective to transfer or retain knowledge; therefore, understanding the role of tacit knowledge retentions as part of knowledge management is becoming increasingly more important to fulfil the organisation strategic goals.

To attain the aim, theoretical and empirical study using (275) samples from different international oil and gas companies have quantitatively assessed three main factors; the

Corresponding Author: AbdulGhani Abdullah Gaghman abdulghanigaghman@ stud.ase.ro

Received: 17 November 2019 Accepted: 6 January 2019 Published: 12 January 2020

Publishing services provided by Knowledge E

(c) AbdulGhani Abdullah Gaghman. This article is distributed under the terms of the Creative Commons

Attribution License, which permits unrestricted use and redistribution provided that the original author and source are credited.

Selection and Peer-review under the responsibility of the EBEEC Conference Committee. strategic impact of tacit knowledge loss, the impact of knowledge and organisational behaviour at the individual level on knowledge retention within the organization.

Based on the study results, both knowledge and organisational behaviour shows direct impact in knowledge retention enhancement. What knowledge and whose knowledge should be emphasised to reduce the impact of crew change. Knowledge management implementation to be the most important factor as Learning and sharing knowledge is affected by the cognitive processes and the way the organisation practice and implement the knowledge share such as mini-workshops, short assignment and community of practice (CoP). The last factor is positive individual attitude, which reflected in more effectiveness knowledge share and transfer. These factors improve tacit knowledge retention and fulfil the strategic goals such as competitiveness advantage and improve the performance, productivity and employee's effectiveness.

Keywords: Oil and Gas, Knowledge Retention, Tacit knowledge, knowledge behaviour, organisational behaviour.

jel CLASSIFICATION codes: M1 Business Administration, M10 General Knowledge Management

\section{Introduction}

During the first decade of the 21st century, the interest in Knowledge Management (KM) has increased with the innovation and learning advance as a result of overall technological and market changes. This was critical for business success and gained 
more competitive advantages. Oil and gas industry as a knowledge-based business has been at the forefront of implementing knowledge management and deploying its techniques because of several factors such depletion of major fields, more complex upstream projects, explore in frontier locations, rapid advances in information and application technologies and the environmental consideration [9].

Oil and Gas (O\&G) companies as intensive-knowledge, high-technology organisations depend highly on employee's accumulated knowledge. On the same time, it is a more turbulent industry which has a higher risk in the term of organisation learning and knowledge retention [8]. Retaining the expert knowledge considered as one of the main challenges mainly in oil and gas business. This knowledge can exit with the employee and cause serious effect on organisation learning and memory capacity.

The latest financial crisis which began in the summer of 2014, plagued the economies of developed and developing countries alike. It turned out that the crisis appeared mainly due to oil prices drop which reduced the overall production and operation. This resulted in about 350 thousand jobs slashed in 2015 only [1]. This has also caused a gap in knowledge mainly the tacit knowledge (know-how and know-what)[19], due to huge amount of accumulated knowledge lost with the employees' departure. Thus, organisation could not learn from the previous experience and began to reinvent the wheel when the situation will back to normal.

\subsection{Problem statement}

Referring to Oil and Gas, statistics; 71 percent of staff is (50) years or older, of which 50 percent will be retired in the next 5 years [2]. Lloyd's Register Energy Survey [14] also shows that $O \& G$ industry will not meet the needs for 2035 . The primary issue is more related to knowledge/skills with 36 percent, and 16 percent due to ageing assets. Commercial barriers 16 percent, regulatory environment 23 percent and adopt new technology 8 percent.

Identifying the critical knowledge, what needs to be captured and consolidated DeLong (2004) (What type of knowledge and from Whom?) is the start questions to be answer based on [16]. Then, investigating knowledge behavioural practice [9] (i.e., learning, knowing, creating, sharing, transferring and applying knowledge). This paper focuses more on the individual behaviour, [10] as 'people' is the key component of knowledge and organisational behaviour (Personality, Motivation, Diversity, Emotions and Attribute)[19]. Finally, highlight the implication of improving knowledge retention for a more effective, efficient and strong competitive advantage organisation. 


\subsection{Research questions/aims of the research}

The aim of this study is to investigate the impact of organisational behaviour at individual's level on tacit knowledge retention in O\&G organisations by analyzing three main factors and investigate to which extent they impact knowledge sharing and retention. Those factors are: The strategic risk of knowledge loss, Knowledge behaviour and Individual behavioural variables reflected in three hypotheses as following:

- H1: Knowledge loss is a strategic risk which impact organisation's overall strategy

- H2: Effective tacit knowledge retention is impacted by KM implementation

- H3: Individual behavioural (attitude) factors impact tacit knowledge retention significantly.

Based on findings, constructive discussion and recommendation has been provided aiming to help managers and organisations to focus on the main behavioural factors that may improve knowledge retention for the benefit of the competitive advantage, productivity and efficiency of the organisation.

\section{Literature Review}

Tacit knowledge is "knowledge-how" which resides in individual mind, behaviour and perceptions. It is not easy to express or formalise, it's difficult to communicate to others. Moreover, it developed through experience, practice and observation [19]. Thus, individuals consider tacit knowledge as intuition rather than a list of systematic instructions to be followed [15].

Chilton [4] identifies four characterisations of Tacit Knowledge as following: first the lack of conscious awareness as it was built over time and the user is not consciously aware of it. Secondly, is the expressibility? Which is the degree to which it is not expressible? A third component of tacitness is demonstrability, which represents the ability of individual to perform tasks based only on seeing the task performed in front of him. A fourth element reflected by the individual ability to apply gaining knowledge from formal or informal learning.

According to [16], tacit knowing can be defined as "the knowledge that resides in people's minds and their experience that is not easily documented" [16]. The term tacit knowledge was first introduced in 1969 by Polanyi in his book 'The Tacit Dimension' [23]. Additionally, Nonaka [19] identifies two main dimensions for tacit knowledge (know-how and know-what), Haron \& Alias [11] summarises other scholar discussions about the TK 
dimension and relates upon the conceptualised dimension of TK as shown in the (Table 1) below.

TABLE 1: Conceptualised Dimension of Individual Tacit Knowledge based on [11].

\begin{tabular}{|c|c|c|}
\hline $\begin{array}{l}\text { Encultured/know-who } \\
\text { (culture, shared understanding, } \\
\text { relationship, corporate mind } \\
\text { set) }\end{array}$ & $\begin{array}{l}\text { Embedded/architectural } \\
\text { (organizing routines, shared } \\
\text { norms, taken-for-granted } \\
\text { routines and interactions) }\end{array}$ & \\
\hline & & $\begin{array}{l}\text { System understanding/know- } \\
\text { why } \\
\text { (know-why,knowledge on } \\
\text { principles of motion, universe law, } \\
\text { systems, schema, reference } \\
\text { methodology) }\end{array}$ \\
\hline $\begin{array}{l}\text { Cognitive/know-what } \\
\text { (mental models, beliefs, } \\
\text { values, schemata, vision, goal, } \\
\text { paradigm knowledge) } \\
\text { Self-transcending/self } \\
\text { motivated } \\
\text { (imagination, aesthetic } \\
\text { experience, improvement) }\end{array}$ & $\begin{array}{l}\text { Embodied/know-how } \\
\text { (action-oriented, context } \\
\text { specific, experiential, } \\
\text { lifetime accumulation of } \\
\text { skills, training and } \\
\text { competencies, ability, skill } \\
\text { to do something, automated } \\
\text { working knowledge (non } \\
\text { analytic behavior, } \\
\text { inspirations, insights, } \\
\text { intuition)) }\end{array}$ & $\begin{array}{l}\text { Technical/know-how } \\
\text { (expertise, skill, practical "know- } \\
\text { how", motor skill) }\end{array}$ \\
\hline Abstract & & \\
\hline
\end{tabular}

\subsection{Strategic impact of knowledge}

Historical data for the major oil and gas companies show that, the productivity increase when the oil and gas companies started to deploy the KM in 1994. Furthermore, the learning process improved and enabled the management to make better decisions [22]. Edwards [7] argues that the oil industry is a leader in KM practice, while other industries have not deployed yet KM initiatives at all. However, the issue is that most of the companies discuss about KM without referring to any KM literature. Nonaka [19] mentioned, though that the interest in knowledge started in 1990 (see Table 2).

Grant held a comprehensive discussion about KM in oil and gas organisations in [9], with many concerns highlighted by several CEOs for oil and gas companies such as Chevron, BP, Total and Schlumberger. The discussion was about the importance of using knowledge to drive learning and improve the knowledge behaviour within the companies. Instead of "knowledge shopping" outside the companies, Organisation need be more effective in retaining the tacit knowledge and made it accessible for another staff. 
TABLE 2: History of KM adoption in Oil and gas Organisations (Source: [9]).

\begin{tabular}{|c|c|c|}
\hline Company & $\begin{array}{l}\text { Adoption } \\
\text { of KM }\end{array}$ & Origins of KM \\
\hline BP & 1996 & $\begin{array}{l}\text { Organizational learning/best practices transfer in } \\
\text { upstream }\end{array}$ \\
\hline Shell & 1995 & $\begin{array}{l}\text { Organizational learning initiatives by corporate } \\
\text { planning (e.g. scenario analysis, cognitive maps) }\end{array}$ \\
\hline Chevron & 1996 & $\begin{array}{l}\text { Best practices transfers \& cost reduction in Chevron's } \\
\text { downstream businesses }\end{array}$ \\
\hline ExxonMobil & 2003 & $\begin{array}{l}\text { In Exxon: application of IT to E\&P. In Mobil, best } \\
\text { practice transfers in downstream }\end{array}$ \\
\hline ConocoPhillips & 1998 & IT support for E\&P \\
\hline Schlumberger & 1997 & IT applications to drilling \\
\hline Halliburton & 1998 & IT applications to drilling and seismic analysis \\
\hline Marathon Oil & 1999 & IT applications to exploration \\
\hline Murphy Oil & 2000 & IT applications to exploration \\
\hline BHP-Billiton & 2000 & $\begin{array}{l}\text { KM uninitiated by IT dept. - but not adopted company- } \\
\text { wide }\end{array}$ \\
\hline $\begin{array}{l}\text { Paragon Eng. } \\
\text { Services Inc. }\end{array}$ & 1999 & $\begin{array}{l}\text { KM practices based upon groupware, intranet, project } \\
\text { les, \& other IT tools }\end{array}$ \\
\hline
\end{tabular}

Like any other industries, oil and gas organisation should manage both types of knowledge ---"explicit" and tacit" --- to achieve the objective of knowledge management. Explicit knowledge can be transferred and shared by or (People-to-information) using information systems as it is more visible, while tacit knowledge which resides in the individual's brain needs more interactive (People-to-People) mechanisms between experts (individuals) and groups (young professionals) such as communities of practice and knowledge sharing portals [18].

According to [9], oil and gas organisations use a more structured learning process aiming to improve the productivity and increase the level of KR. In general, the tools and systems used in oil and gas can be grouped in two main groups:

1. Technology based (Corporate database, Knowledge hub)

2. People based

- Communities of Practice

- Best Practice Groups

- Peer Review Groups

- Mentorship programs

- Professional training

Preventing "Knowledge destruction" in oil and gas business is a crucial priority due to high attrition rate in general. Some related it to current crisis as started in late 2014, which caused many companies to choose downsizing as a strategy to reduce cost. [20] suggested that this situation could be overcome not by searching for a technological solution. He stressed the importance of setting clear and relevant 
objectives for the organisation, then addressing the knowledge needs of individuals, groups or communities of practice (CoP.), which may be achieved through a knowledge management system particularly by a set of proper knowledge retention strategies.

Therefore, to avoid the knowledge loss which leads to strategic problems, KR should be applied within the organisation system by examining four perspectives as suggested by [5]: the strategic view, the human resources view, the operational content view and knowledge management view. Doan et al. [6] Knowledge Retention model investigate the key factors that influence the KR process within an organisation. Doan's model includes five key factors critical for KR depicted in the (Figure 1).

\section{Top Management \\ Support}

ICT Tools

\title{
Knowledge Retention Process
}

\author{
Critical Knowledge
}

Business Process Focused

$\begin{array}{lcc}\text { Human } & \text { Knowledge } & \text { Leaming } \\ \text { Resource } & \text { Retention } & \text { Culture } \\ \text { Practices } & \text { Strategy } & \end{array}$

Figure 1: The Model of Knowledge Retention (source: [6]).

To address the strategic impact of knowledge loss, as summarized in Figure (2) and its influence on knowledge retention we should identifying two main parameters: whose knowledge and what type of knowledge at different level of retention [16] which consider the first factor for this research to investigate as shown below.

Overall, the literature review shows that quite few researches conducted in knowledge retention with the organisation behavioural perspective and seldom in the regard of oil and gas organisation. For these reasons, this empirical study will help the management to avoid knowledge loss and improve the its retention. 


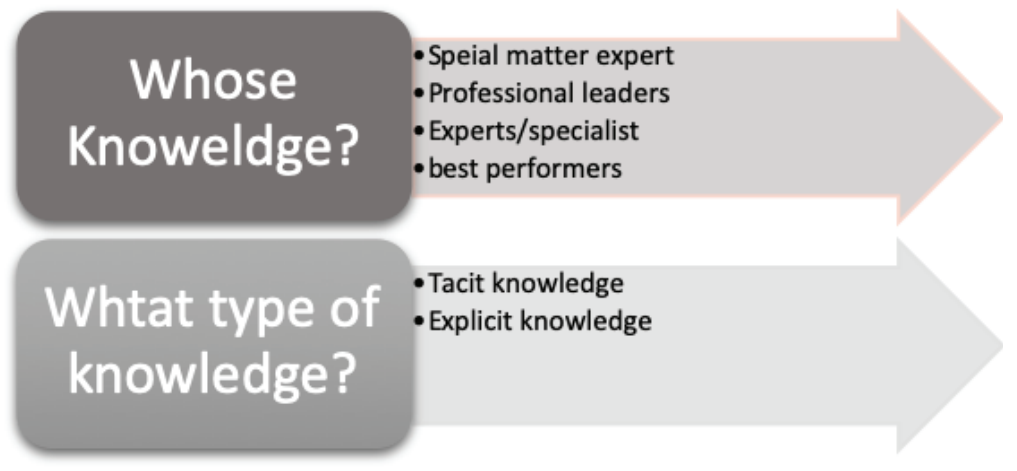

Figure 2: Identifying the Strategic Impact of Knowledge Loss that Influence KR.

\subsection{Knowledge behavioural factors}

Knowledge retention via implementing knowledge management techniques, i.e. capture, transfer and retention is needed for all the organization as it considers a high intellectual asset value and a strategic resource in maintaining organization's competitive advantage [8]. In the oil and gas business, there is a significant risk of losing key knowledge, which need a knowledge management plan in place to transfer this knowledge to the young generations before it got lost.

Martins [16] classified knowledge processes into two main types: first, Cognitive processes (such as Learning and knowing) and second, Construction processes (such as creating, sharing, transferring and applying) on which we focus in this research. The knowledge constructive processes (knowledge creation, acquisition, refinement, storage, transfer, sharing and implementation) have link to a good support for the organisational overall processes involving innovation, individual learning, collective learning and collaborative decision making [13].

1. Cognitive Processes

- Learning Behaviour

- Knowing behaviour

2. Constructive Processes / behaviour

- Knowledge Creating

- Knowledge Sharing

- Knowledge Transfer

- Knowledge application

In summary, Knowledge processes, either cognitive or constructive, have been approached both theoretically. The tacit knowledge concept is, however, not so 
thoroughly described as the explicit one. Those processes considered as the second factor to be investigated through the online survey to assess to what extent they impact/impede the knowledge retention (Figure 3).

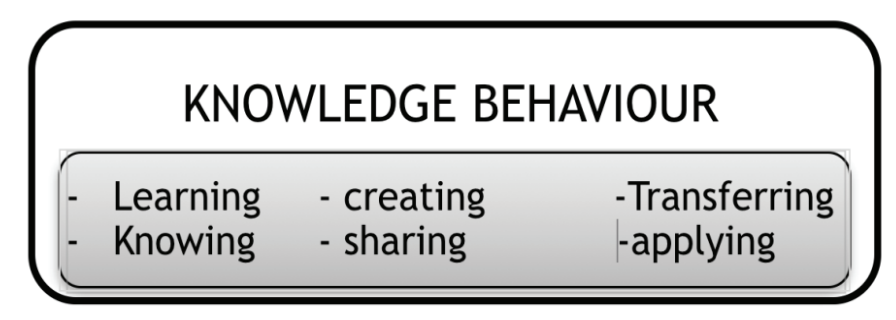

Figure 3: Key Knowledge Behaviour that Impacts the Knowledge Retention within the Organisation.

\subsection{Organisational behavioural factors}

It is vital to understand the role of organisational behaviour factors at individual level that may influence knowledge retention based on the independent behavioural factors at individual level such as Diversity, Personality, Motivation, Value, Emotions and Perception [19]. Griffin highlights the importance of understanding organisational behaviour to enable managers to lead the organisation in more perspectives the human sides of management (People as organisations, people as resources, and people as people) [10]. Therefore, knowledgeable people considered as a source of competitive advantage and growth for the potential of human resources system [19].

Knowledge retention can be treated as a dependent variable in the organisation, which means knowledge retention in the organisations is influenced by several factors [16]. There are main determinants of the dependent factors mentioned above, presented by $[16,19]$ will be our focus in this research as summarised in (Figure 4).

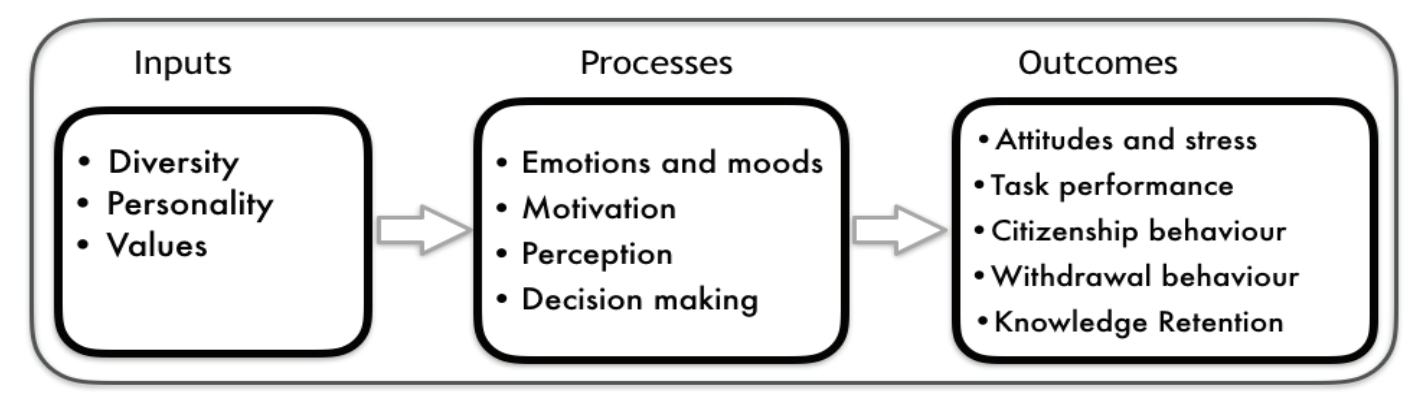

Figure 4: The OB Model at Individual Level -- (adopted from [19]). 


\section{Research Methods}

This research follows the Mono Quantitative Methodology using single data collection method via online questionnaire survey. The questionnaire was designed to gain descriptive profile of each question answered by respondents. Targeted population planned to target 500 samples from different international oil and gas companies of which 275 respondents were received.

Self-completed questionnaire has been developed to collect data from individuals in international oil and gas companies targeting the attitude, opinion questions and organisational practices. 10 pages Questionnaire has distributed to respondents through the internet using (google survey) aiming to enhance the validity of the research findings.

The Likert scale (1 disagree, 5 strongly agree) questionnaire contains three sections, to allow participants to do it in few minutes. Each section reflects one of the predefined objectives of this research, in a logical order stressing its impact on knowledge retention as following (Figure 7):

Factor 1 (H1): People knowledge loss strategic risks $\quad$ (15 questions)

Factor $2(\mathrm{H} 2)$ : Knowledge behaviour (Management) (14 questions)

Factor $3(\mathrm{H} 3)$ : Individual behaviour (29 questions)

In general, some criteria have been implemented when formulating the question statements based on [3] such as to use simple languages, avoid advance question, positive questions and each question target only one item. Based on the result 4 respondents out of 275 respondents answered partially the survey and has been excluded.

To reach main goals of this research, data analysis conducted in a descriptive manner also investigate if there is any trend or pattern in the data which can be recognised, further analysis such as Cronbach's Alpha, testing for significant relationships and difference (i.e. Testing for Normality, Chi-square test of association, Pearson correlation) and multiple regression analysis has been conducted using IBM SPSS software. Qualitatively analysis result has presented in statistic measures such as (means, frequencies and percentage). And recorded in a text report utilising graphs, tables, charts to draw conclusions and made recommendations about the knowledge retention and its link to individual behavioural factors.

Validation assessment start with Cronbach's Alpha measure the internal consistency which was very good $>90 \%$, the relationship between the composite factors and the knowledge retention satisfaction (dependent factor) has been measured by Chi-square 


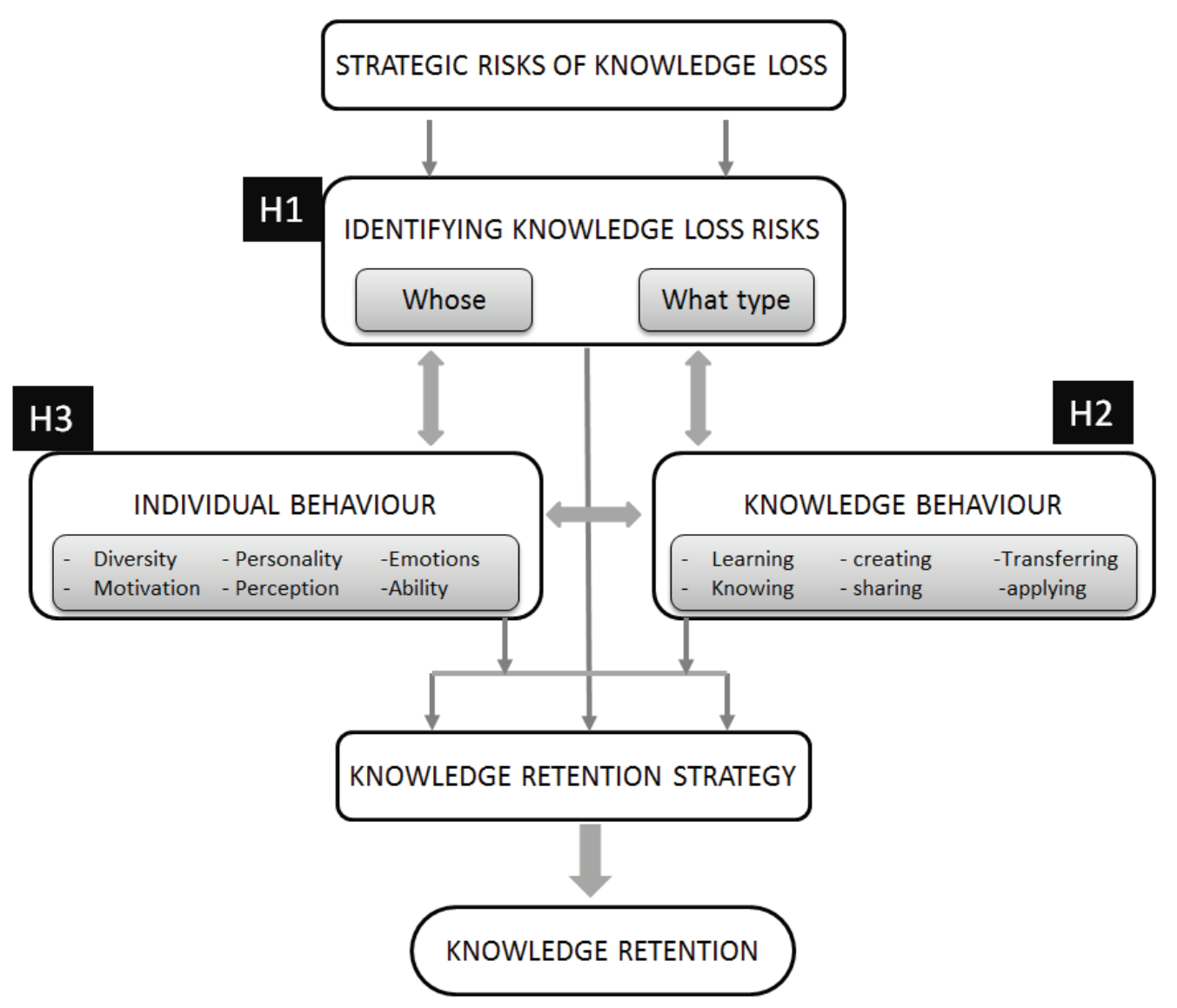

Figure 5: Research Questionnaire layout to answer the theories.

Association Test and Pearson's Correlation (the magnitude of the correlation is strong $(0.5<|r|<0.7)$.

\section{Discussion and Findings}

Knowledge retention as a dependent factor required indirect measure [21]. Questionnaire was designed to address each factor by several questions which allow us to create composite variable for each factor, which consists of the average mean of all the factor components. 


\subsection{Descriptive analysis}

Quantitative research method was used to achieve this empirical study based on intensive literature review of knowledge and organisational behavioural. The Questionnaire was designed to target upstream engineers who work international oil and gas companies focusing on tacit knowable retention.

General Demographical profile for the respondent shown in the (Figure 6). The statistic results for the 3 main factors as per the research theory shown in (Table 3); Factor $1(\mathrm{H} 1)$ : People knowledge loss strategic risks, Factor $2(\mathrm{H} 2)$ : Knowledge behaviour, Factor $3(\mathrm{H} 3)$ : Individual behaviour. The descriptive statistics depicted in (Tables 3).

Data analysis for factor I ( $\mathrm{H} 1$ ) represented mainly by two questions discuss this factor; 1) The Importance of developing and keep knowledge within the organisation resulted in "agree" [mean value 4]. But when it comes to consider 2) Knowledge loss as risk the result was "Neutral" [mean value 3]. A conclusion can be made from these points as following; Staff is aware about KM strategy, but they don't consider knowledge loss as a real strategic risk.

For factor II ( $\mathrm{H} 2)$ The knowledge management mainly the transfer and share initiatives shows low satisfaction result "disagree" [mean value 2.1, Skewness=0.2]. The reason behind it can be explained due to poor knowledge management/leading and lack of knowledge share activities. Moreover, the companies still focus on explicit more than the tacit knowledge. For Factor III (H3), Based on the survey result, we can conclude that the individual behaviour tent to be in the higher side "agree" [Mean=3.5, Skewness=-0.6], which reflected in the positive attitude [Mean $=3.62$, Skewness=-0.62]. Consequently, the organisation should focus on the component of organisational behaviour at individual level to have a positive attitude which reflected later as knowledge retention and improve the employee's effectiveness and decision making.

\subsection{Empirical study discussion}

\subsubsection{Factor I - Strategic risk of knowledge loss}

Strategic risk of knowledge loss was formulated by identifying; what type of knowledge should be retained and whose individual we should target to retain aiming to improve the performance and gain more competitive advantage. In more details, specific questions have been designed to address these questions as part of the survey and shows in (Figure 7). 


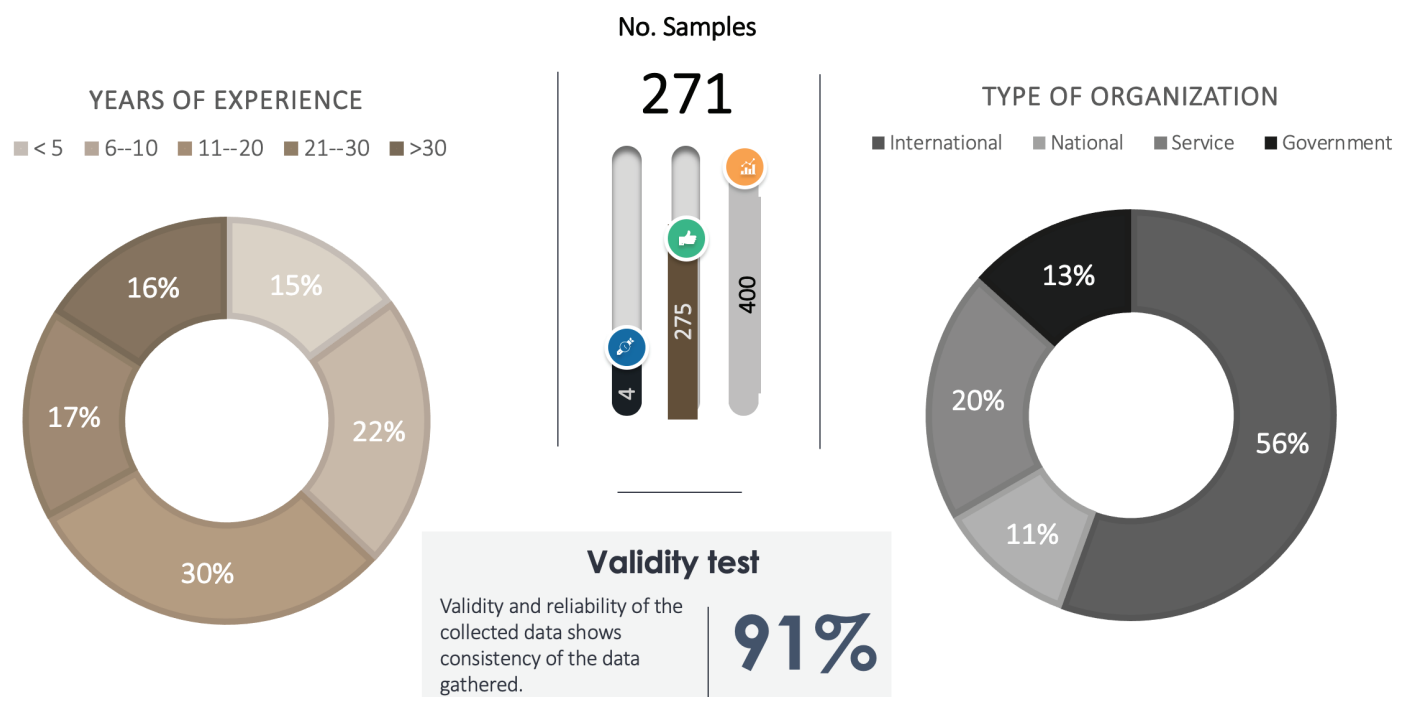

Figure 6: Demographic profiel for the research respondent via online survey.

The survey result shows that, high experienced employees (73\%), experts and specialists (66\%) and best performers (41\%) are the key individuals within the organisation whose knowledge, if lost, could affect the organisation performance and effectiveness. As a sequence of knowledge loss, it may cause failure to share ideas, duplication of work, repetition of mistake, loss of market share and inefficiency in using latest technology.

\section{Whose knowledge We Should Retain?}

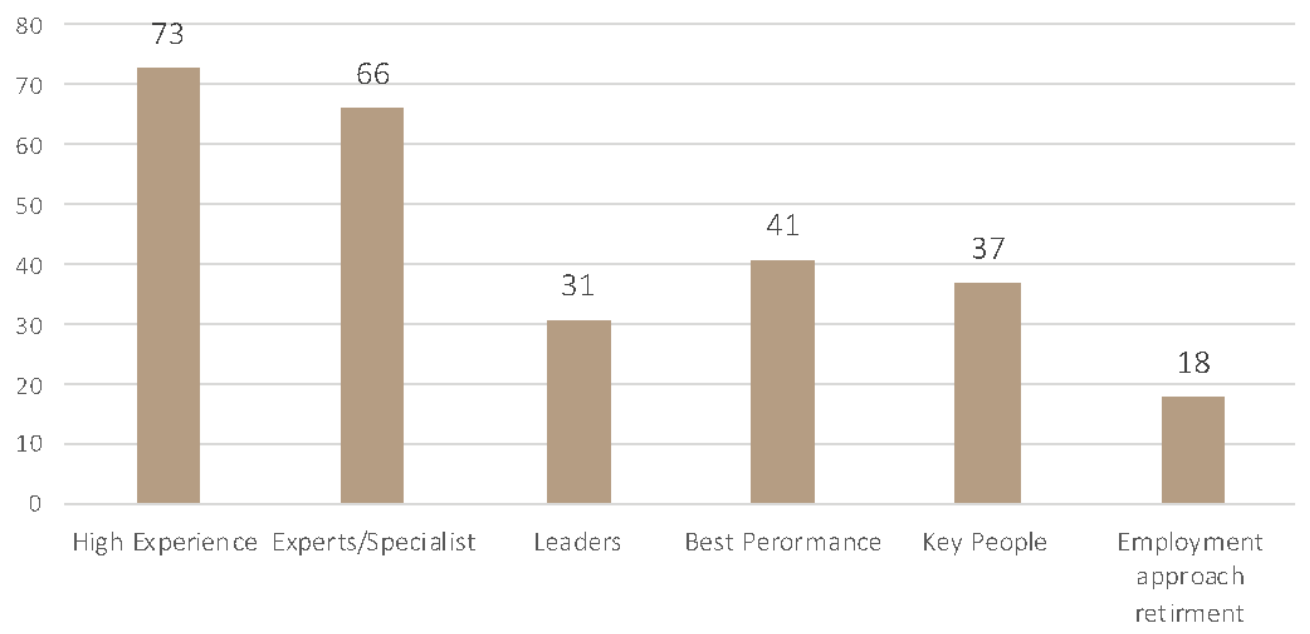

Figure 7: Whose knowledge We Should Retain?

This study emphasised on the vital role of human resources and management support to implement knowledge retention as one element of the organisation strategy. Staff retention, Personal development, mentoring and coaching and performance management is critical to leverage the knowledge retention within the organisation. 
TABLE 3: Descriptive analysis for Composite Factors.

\begin{tabular}{|c|c|c|c|c|}
\hline \multicolumn{5}{|c|}{ Descriptives } \\
\hline & & & Statistic & Std. Error \\
\hline \multirow[t]{13}{*}{ Strategic_Risk } & \multicolumn{2}{|l|}{ Mean } & 3.2661 & .05754 \\
\hline & \multirow{2}{*}{$\begin{array}{l}95 \% \text { Confidence Interval } \\
\text { for Mean }\end{array}$} & Lower Bound & 3.1527 & \\
\hline & & Upper Bound & 3.3795 & \\
\hline & \multicolumn{2}{|l|}{$5 \%$ Trimmed Mean } & 3.2815 & \\
\hline & \multicolumn{2}{|l|}{ Median } & 3.2667 & \\
\hline & \multicolumn{2}{|l|}{ Variance } & .732 & \\
\hline & \multicolumn{2}{|l|}{ Std. Deviation } & .85540 & \\
\hline & \multicolumn{2}{|l|}{ Minimum } & 1.00 & \\
\hline & \multicolumn{2}{|l|}{ Maximum } & 4.93 & \\
\hline & \multicolumn{2}{|l|}{ Range } & 3.93 & \\
\hline & \multicolumn{2}{|l|}{ Interquartile Range } & 1.27 & \\
\hline & \multicolumn{2}{|l|}{ Skewness } & -.228 & .164 \\
\hline & \multicolumn{2}{|l|}{ Kurtosis } & -.512 & .326 \\
\hline \multirow[t]{13}{*}{ Kbehaviour } & \multicolumn{2}{|l|}{ Mean } & 3.1963 & .05898 \\
\hline & \multirow{2}{*}{$\begin{array}{l}95 \% \text { Confidence Interval } \\
\text { for Mean }\end{array}$} & Lower Bound & 3.0801 & \\
\hline & & Upper Bound & 3.3125 & \\
\hline & \multicolumn{2}{|l|}{$5 \%$ Trimmed Mean } & 3.2146 & \\
\hline & \multicolumn{2}{|l|}{ Median } & 3.2308 & \\
\hline & \multicolumn{2}{|l|}{ Variance } & .769 & \\
\hline & Std. Deviation & & .87673 & \\
\hline & Minimum & & 1.00 & \\
\hline & Maximum & & 5.00 & \\
\hline & Range & & 4.00 & \\
\hline & Interquartile Range & & 1.23 & \\
\hline & Skewness & & -.251 & .164 \\
\hline & Kurtosis & & -.323 & .326 \\
\hline \begin{tabular}{|l|} 
Attitude \\
\end{tabular} & Mean & & 3.6171 & .05293 \\
\hline & $95 \%$ Confidence Interval & Lower Bound & 3.5128 & \\
\hline & & Upper Bound & 3.7214 & \\
\hline & 5\% Trimmed Mean & & 3.6420 & \\
\hline & Median & & 3.5000 & \\
\hline & Variance & & .619 & \\
\hline & Std. Deviation & & .78693 & \\
\hline & Minimum & & 1.63 & \\
\hline & Maximum & & 5.00 & \\
\hline & Range & & 3.38 & \\
\hline & Interquartile Range & & 1.13 & \\
\hline & Skewness & & -.282 & .164 \\
\hline & Kurtosis & & -.325 & .326 \\
\hline Individual_B & Mean & & 3.5750 & .04368 \\
\hline & $95 \%$ Confidence Interval & Lower Bound & 3.4889 & \\
\hline & for Mean & Upper Bound & 3.6611 & \\
\hline & $5 \%$ Trimmed Mean & & 3.6023 & \\
\hline & Median & & 3.5714 & \\
\hline & Variance & & .422 & \\
\hline & Std. Deviation & & .64935 & \\
\hline & Minimum & & 1.43 & \\
\hline & Maximum & & 4.79 & \\
\hline & Range & & 3.36 & \\
\hline & Interquartile Range & & .89 & \\
\hline & Skewness & & -.530 & .164 \\
\hline & Kurtosis & & .616 & .326 \\
\hline
\end{tabular}
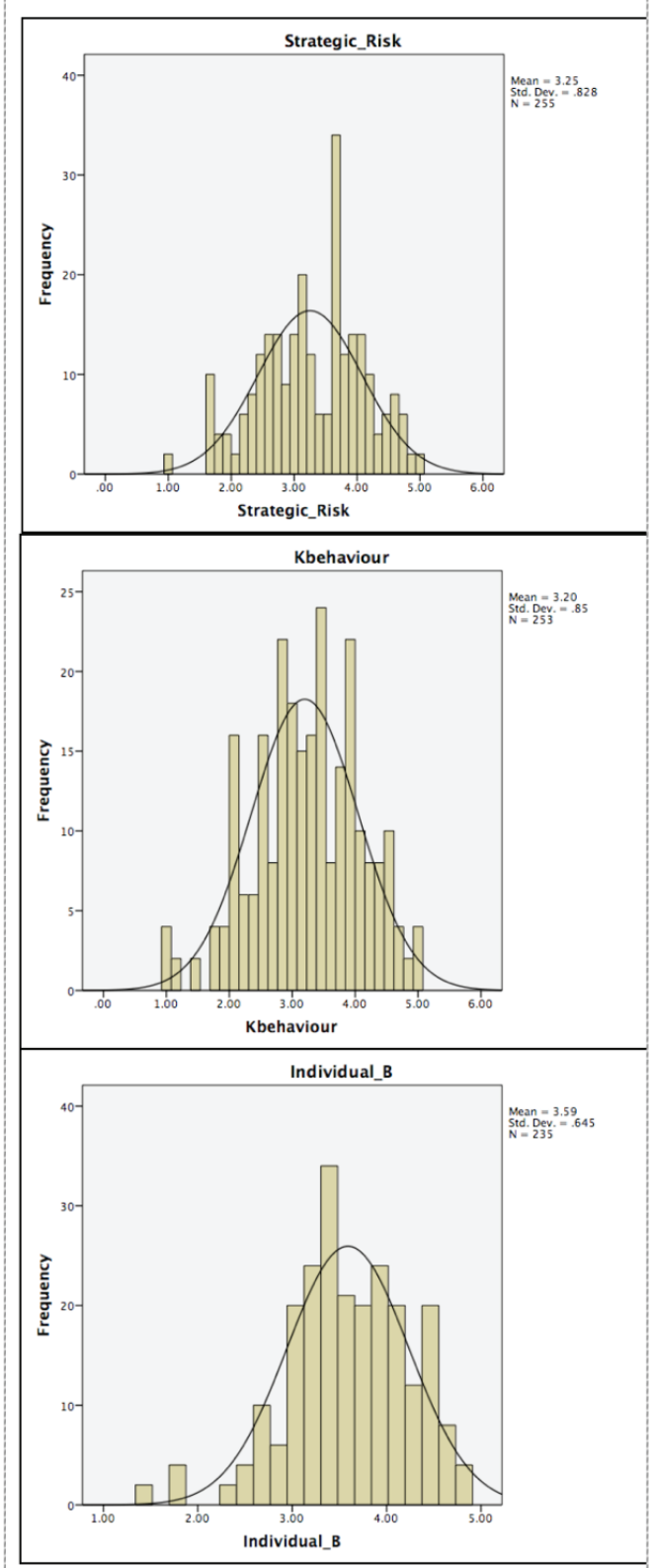

\subsubsection{Factor II - Knowledge behaviour}

The knowledge behaviour was identified as a cognitive and constructive process. The way the organisation is handle and mange those processes would impact the knowledge retention and reduce the knowledge loss.

The study investigates the current methods used for knowledge sharing and retention within the organisation and the survey results depicted the top method used is documentation (20\%) and Lesson learned (18\%) best practice (17\%) and surprisingly CoP. have only (8\%). These results came contradicting the literature and KM discussions 
such as (APQC and Schlumberger) where they specify that, KR requires more than documentation or written reports (Figure 8).

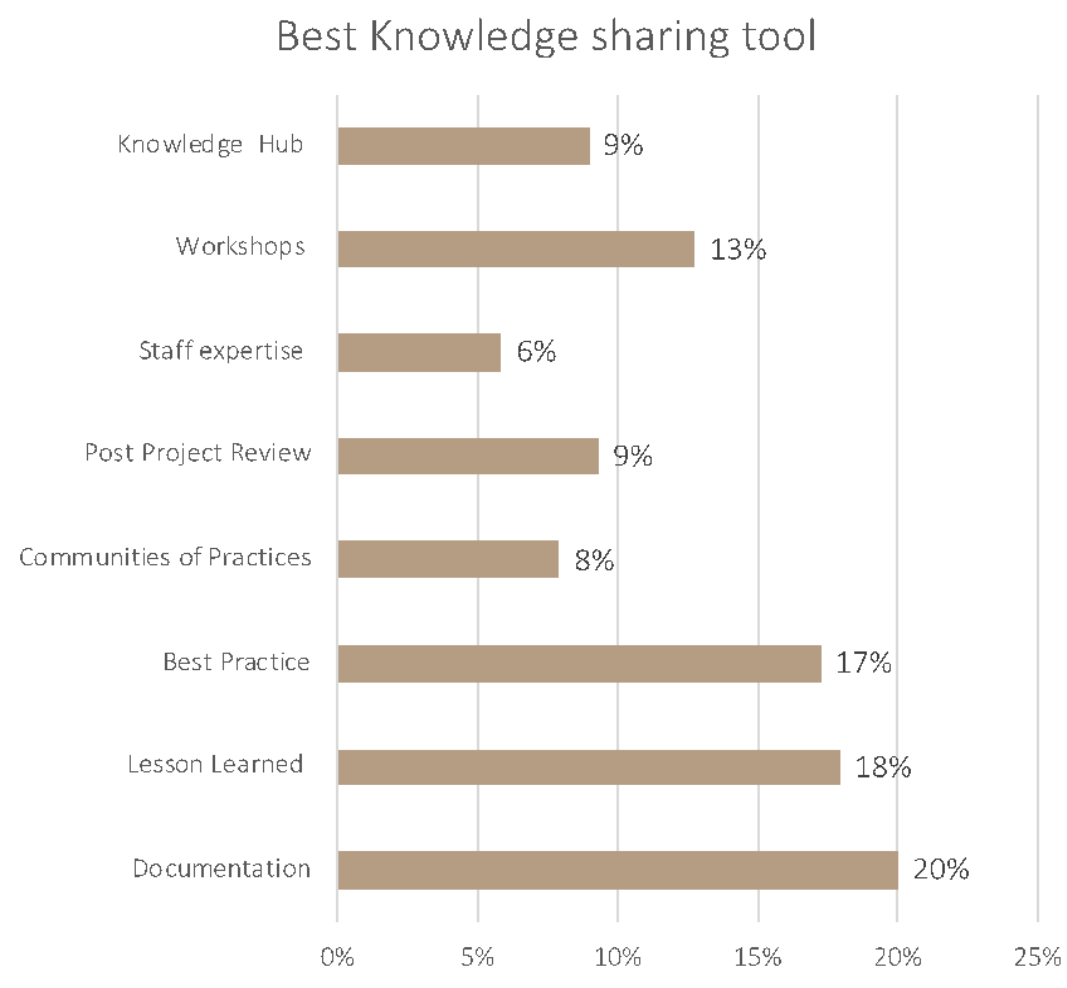

Figure 8: Different Sharing Knowledge Methods Based on the Survey Results.

\subsubsection{Factor III - Individual behaviour}

Based on Robbins' Organisational Behavioural Model [19], the organisational behaviour at individual level was discussed in the research to determine the impact on tacit knowledge retention. The key components of the individual behavioural have been investigated separately such as (Diversity, Emotion, Personality, Values, ...etc).

First observation that, Diversity elements (demographical variables) shows dependency from the main composite factors which in line with [12] study result. Personality and Value affect job performance, Emotions and positive mood is linked to effective decision making. Providing reward and recognition, increase employee motivation for revealed technical excellence and knowledge sharing.

Empirical results show the need of having a positive attitude which can be achieve via understanding and caring about individual's behaviour elements. Of which will leverage the knowledge within the organisation, increase the job satisfaction and better performance which in line with Robbins and Martins theory. The positive attitude increases 
the intention of sharing, which reduce the knowledge loss and in consequence improve tacit knowledge retention within the organisation.

The study emphasised on the perception and motivation for the individual to share knowledge. Result shows that $45 \%$ considered sharing knowledge is beneficial for the staff comparing to $31 \%$ who share for personal satisfaction. This result is expected as the oil and gas considered as highly technical organisation, so the individual motivated to be technical leader and they expected to have an influence on others through his or her direct interactions with others, such as mentoring relationship, community leadership and professional visibility.

On the other hand, $42 \%$ of the employee shares knowledge to improve the reputation of the organisation and $26 \%$ to be positively noticed in the organisation. The reason behind that is most of the international companies offer only short-term contracts, so the staffs try to market themselves and gain as many credentials to be get an extension or to be used in the next move/positions. This reflect the important of personal perception and motivation to improve the knowledge share and, consequently, to retain knowledge within the organisation.
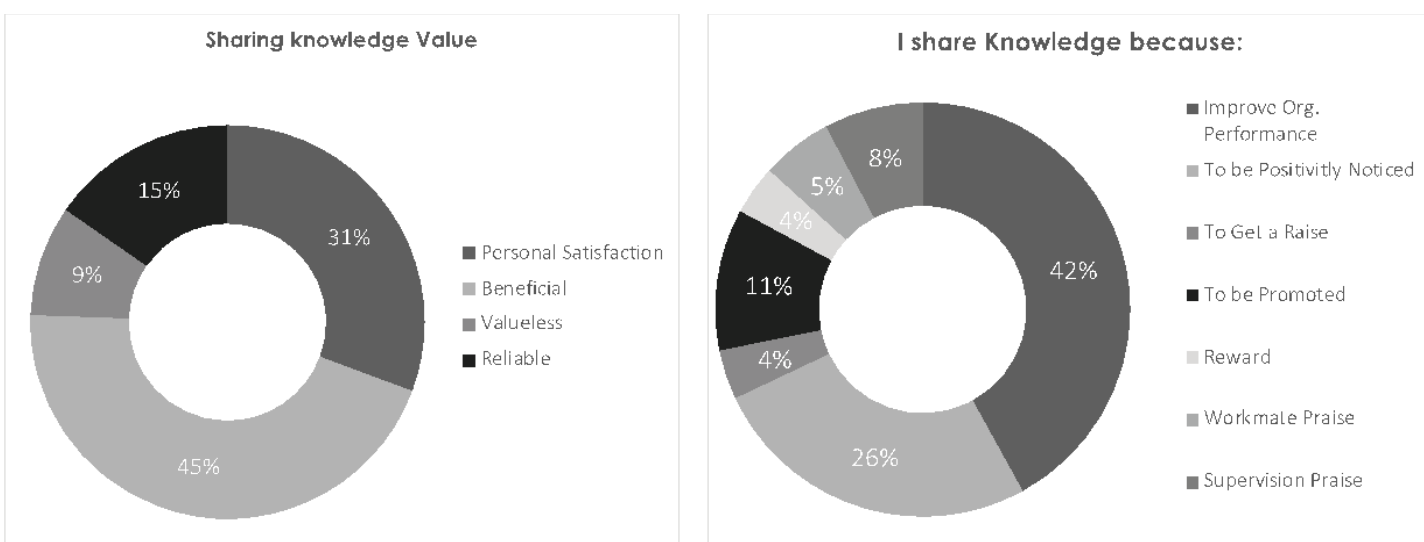

Figure 9: Perception and Motivation for Knowledge Share based on Survey Results (Percentage) N= 271.

\subsection{Interrelationship and correlation result with the main factors}

Inter-correlation between factors shows, a very strong inter-correlation between the strategy risks of losing knowledge, knowledge behaviour and individual behaviour $[|r|$ $>0.7$ in grey shade (Figure 10). The direction of the relationship is positive, meaning that, these variables tend to increase together (i.e., more awareness of knowledge behaviour (practice and implementation) is associated with more tacit knowledge retention) as depicted the result in (Table 7). 
TABLE 4: Pearson Cross Correlation Results for the Key Factors.

\begin{tabular}{|l|c|c|c|c|}
\hline & \multicolumn{4}{|c|}{ Correlations } \\
& $\begin{array}{c}\text { Strategic } \\
\text { Risk }\end{array}$ & $\begin{array}{c}\text { Knowledge } \\
\text { Behaviour }\end{array}$ & Attitude & $\begin{array}{c}\text { Individual } \\
\text { Behaviour }\end{array}$ \\
\hline Strategic Risk & 1 & 0.919 & 0.730 & 0.779 \\
\hline Knowledge behaviour & 0.919 & 1 & 0.770 & 0.811 \\
\hline Attitude & 0.730 & 0.770 & 1 & 0.908 \\
\hline Individual Behaviour & 0.779 & 0.811 & 0.908 & 1 \\
\hline
\end{tabular}

The correlation coefficient between those factors and the dependent factor $(K R)$ is strong $[0.5<|r|<0.7]$ (Table 8). The white boxes with white boxes in (Figure 10) and can be predictable from multiple regression model.

TABLE 5: Results of Significant Relationship Test for Key Factor Variables vs the strategic risk.

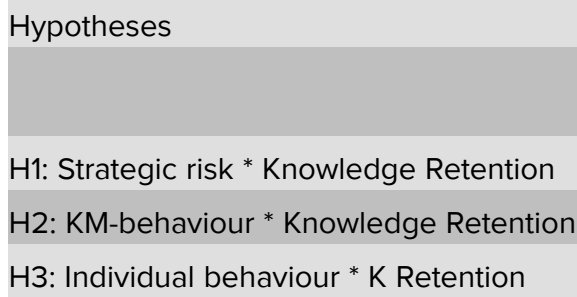

\begin{tabular}{|c|r|}
\hline \multicolumn{2}{|c|}{ Chi-Square Tests } \\
\hline Value & df \\
\hline 149.34 & 45 \\
\hline 135.80 & 43 \\
\hline 178.14 & 55 \\
\hline
\end{tabular}

\begin{tabular}{|c|c|}
\hline Pearson's R. Correlation \\
\hline Pearson's R & $\begin{array}{c}\text { Asym. Std. } \\
\text { Err }\end{array}$ \\
\hline 0.652 & 0.033 \\
\hline 0.639 & 0.033 \\
\hline 0.562 & 0.045 \\
\hline
\end{tabular}

More analysis shows that, knowledge behaviour reflected in a positive correlation (Very strong correlation $>0.90$ ) where the linear regression explains $83 \%$ of the variance in the data. These conclude that, well established knowledge practice / implementation leads to more knowledge retention of which turns in improve knowledge retention within the organisation.

\section{Conclusions}

Quantitative research method was used to achieve this empirical study based on intensive literature review of knowledge and organisational behavioural. The Questionnaire was designed to target international oil and gas staff focusing on tacit knowable retention. The overall reliability based on Cronbach Alpha coefficient shows internal consistency with (0.91).

The research theories have been proved the research hypotheses. However, the $\mathrm{H} 2$ (Effective tacit knowledge retention is impacted by $\mathrm{KM}$ implementation) appeared as the most vital factor ( $\mathrm{Pr}>0.91)$. In conclusion, knowledge and organisational behaviour has a direct impact to improve the knowledge retention within the oil and gas organisation. What knowledge and whose knowledge should be addressed to reduce the impact of crew change. Knowledge management implementation to be the most important factor, 


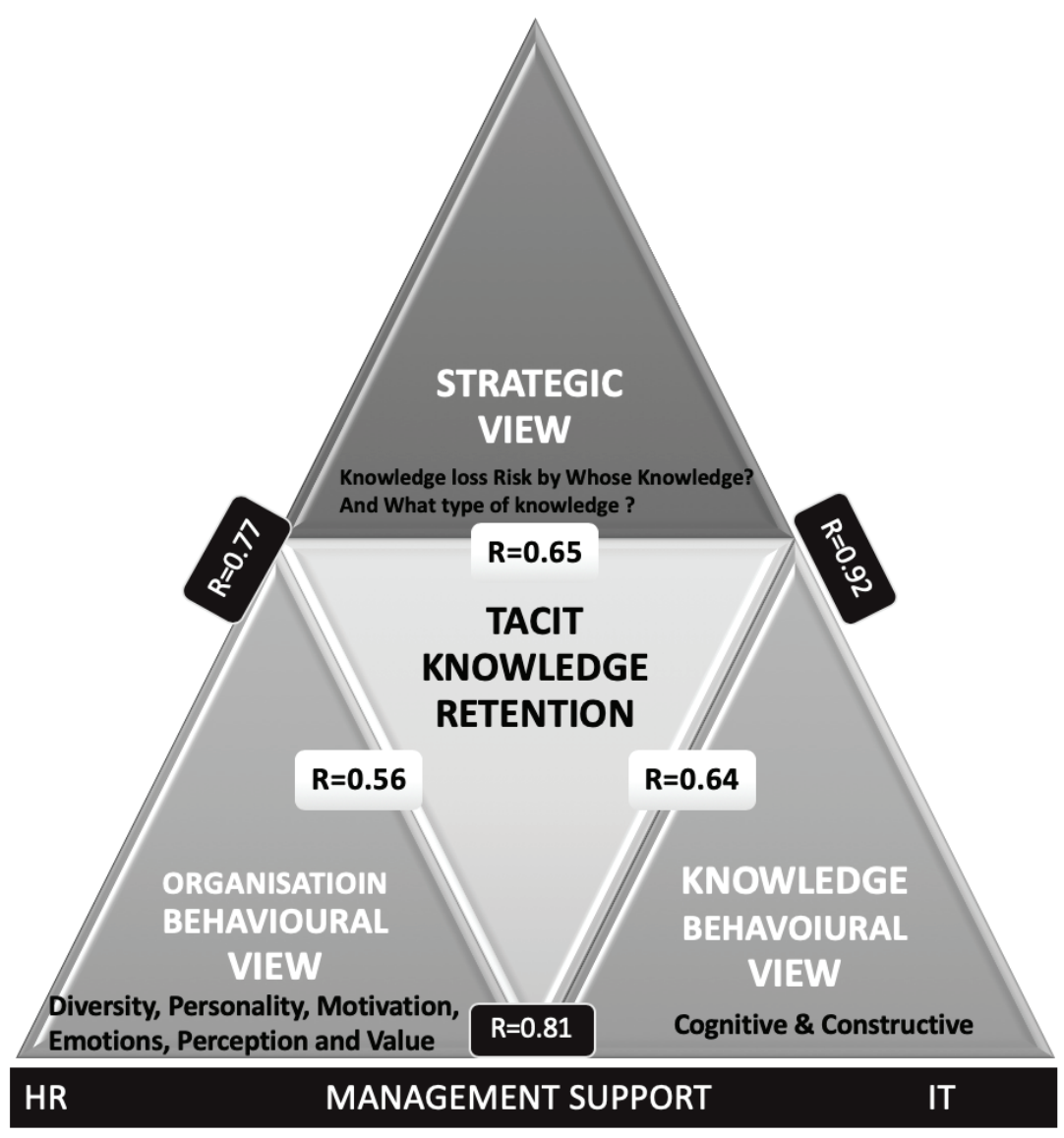

Figure 10: Tacit Knowledge Retention Model based on the research results.

of which learning and sharing knowledge is affected by the cognitive processes and the way the organisation practice and implement the knowledge.

In oil and gas business the best method for knowledge sharing and retention is to organize periodically interactive workshops, active community of practice (CoP.) and increase the number of short assignments, these activities will increase the direct contact with the highly experience and experts staff for the benefit for the young professional.

The last element is maintaining positive individual attitude, of which will be reflected in more intention to share and willing to help which in turn lead to more effective knowledge share and retention. These elements improve tacit knowledge retention and fulfil the strategic goals such as improve the performance and effectiveness of the employees.

This study emphasised on the vital role of human resources and management support to implement knowledge retention as one element of the organisation strategy. Staff 
retention, Personal development, mentoring and coaching and performance management is critical to leverage the knowledge retention within the organisation.

Although, the research achieved its goals, there were some restriction related to limited geographical access where the focus group, interview or open question may enrich the research and address hiding subject and derive more information to be use in the study. On the other hand, large number of employees have been laid-off and their contract has been terminated recently, this might affect the respondent and the way they react to the survey. Further studies can investigate in detail the knowledge processes mainly the tools and technique applied in oil and gas organisation (such as the community of practice CoP., Knowledge hub). With clear focus on success measure, value added and effectiveness to the knowledge retention practice.

\section{Acknowledgment}

Nobody has been more important to me in the pursuit of this project than the members of my family. I would like to thank my loving and supportive wife, Zainab, and my three wonderful children, Ahmed, Amjad and Ali, who provide unending inspiration.

\section{References}

[1] AAPG American Association of Petroleum Geologist Workshop event, 2016. [Online] Retrieved from http://www.aapg.org/global/middleeast/events/workshop/articleid/ 24334/aapg-eage-seg-spe-the-knowledge-management-challenge\#149252092contacts)(accessed: 23rd December 2016).

[2] Birenbaum, K. 2015. The 'Great Crew Change' [Online] Retrieved from http://www. ogfj.com/articles/print/volume-12/issue-4/features/the-great-crew-change.html (accessed: 13rd Jun 2016).

[3] Bryman, A., 2015. Social research methods. Oxford university press.

[4] Chilton, M.A. and Bloodgood, J.M., 2007, January. The dimensions of tacit \& explicit knowledge: A description and measure. In System Sciences, 2007. HICSS 2007. 40th Annual Hawaii International Conference on (pp. 188a-188a). IEEE.

[5] DeLong, D.W., 2004. Lost knowledge: Confronting the threat of an aging workforce. Oxford University Press.

[6] Doan, Q.M., Rosenthal-Sabroux, C. and Grundstein, M., 2011. A Reference Model for Knowledge Retention within Small and Medium-sized Enterprises. In KMIS, pp. 306-311. 
[7] Edwards, J.S., 2008. Knowledge management in the energy sector: Review and future directions. International Journal of Energy Sector Management, 2(2), pp.197217.

[8] Fisher, S.R. and White, M.A., 2000. Downsizing in a learning organisation: are there hidden costs? Academy of Management Review, 25(1), pp.244-251.

[9] Grant, R.M., 2013. The Development of Knowledge Management in the Oil and gas Industry/El desarrollo de la Dirección del Conocimiento en la industria del petroleo y gas. Universia Business Review, (40), p.92.

[10] Griffin, R.W., Phillips, J.M. and Gully, S.M., 2014. Organisational behaviour: Managing people and organisations. Nelson Education.

[11] Haron, H. and Alias, R.A., 2005. Conceptualization of tacit knowledge dimension. In Proceedings of the Postgraduate Annual Research Seminar, pp. 12-17.

[12] Ismail, M.B. and Yusof, Z.M., 2009. Demographic factors and knowledge sharing quality among Malaysian government officers. Communications of the IBIMA, 9, pp.1-8.

[13] King, W. R., 2009. Knowledge management and organisational learning (pp. 3-13). Springer US.

[14] Lloyd 2015. Lloyd's Register Energy. [Online] Retrieved from http://www.Ir.org/en/ energy/news/aog-survey-reveals-skills-and-knowledge-shortage-as-the-criticalchange-issue.aspx (accessed on: 8th November 2016).

[15] Lubit, R. (2001). Tacit knowledge and knowledge management: The keys to sustainable competitive advantage. Organisational Dynamics, 2991), 164-178.

[16] Martins, E.C. and Martins, N., 2011. The role of organisational factors in combating tacit knowledge loss in organisations. Southern African Business Review, 15(1).

[17] Nonaka, I., 2002. A dynamic theory of organisational knowledge creation. The strategic management of intellectual capital and organisational knowledge, pp.437462.

[18] Nonaka, I., 2008. The knowledge-creating company. Harvard Business Review Press.

[19] Robbins, S., Judge, T.A., Millett, B. and Boyle, M., 2013. Organisational behaviour. Pearson Higher Education AU.

[20] Riddell, M.R., 2011. Knowledge Retention in Oil and gas Companies: Focus on the Individual.

[21] Rowe, K., 2006. The measurement of composite variables from multiple indicators: Applications in Quality Assurance and Accreditation Systems--Childcare. Camberwell, Victoria: Australian Council for Educational Research. 
[22] Smith, R., 2001. Schlumberger Oil Field Review. [Online] Retrieve from: http://www. slb.com/\$sim\$/media/Files/resources/oilfield_review/ors01/spr01/p66_83.ashx (accessed on $9^{\text {th }}$ October 2016)

[23] Wamitu, S.N., 2015. Tacit Knowledge Sharing in Public Sector Departments in Kenya. Open Journal of Business and Management, 3(01), pp.109. 